\title{
Seismic Performance Analysis of RCC Multi-Storied Buildings with Plan Irregularity
}

\author{
Mohaiminul Haque ${ }^{1}$, Sourav Ray ${ }^{1,}$, Amit Chakraborty ${ }^{2}$, Mohammad Elias $^{1}$, Iftekharul Alam ${ }^{1}$ \\ ${ }^{1}$ Department of Civil and Environmental Engineering, Shahjalal University of Science and Technology (SUST), Sylhet, Bangladesh \\ ${ }^{2}$ Department of Civil Engineering, Leading University, Sylhet, Bangladesh
}

\section{Email address:}

sourav.ceesust@gmail.com (S. Ray), sourav-cee@sust.edu (S. Ray), pallab87.sust@gmail.com (M. Haque)

${ }^{*}$ Corresponding author

\section{To cite this article:}

Mohaiminul Haque, Sourav Ray, Amit Chakraborty, Mohammad Elias, Iftekharul Alam. Seismic Performance Analysis of RCC Multi-Storied Buildings with Plan Irregularity. American Journal of Civil Engineering. Vol. 4, No. 3, 2016, pp. 68-73. doi: 10.11648/j.ajce.20160403.11

Received: March 20, 2016; Accepted: March 28, 2016; Published: April 21, 2016

\begin{abstract}
Bangladesh is one of the most earthquake prone areas in South-Asia and Sylhet is the most seismic vulnerable region in Bangladesh. Seismic performance analysis is highly recommended to ensure safe and sound building structures for this region. To get better performance from reinforced concrete (RCC) structure, new seismic design provisions require structural engineers to perform both static and dynamic analysis for the design of structures. The objective of the this study is to carry out static and dynamic analysis i.e. equivalent static analysis, response spectrum analysis (RSA) and time history analysis (THA) over different regular and irregular shaped RCC building frame considering the equal span of each frame as per Bangladesh National Building Code (BNBC)- 2006. In this study, four different shaped (W-shape, L-shape, Rectangle, Square) ten storied RCC building frames are analysed using ETABS v9.7.1 and SAP 2000 v14.0.0 for seismic zone 3 (Sylhet) in Bangladesh. Comparative study on the maximum displacement of different shaped buildings due to static loading and dynamic response spectrum has been explored. From the analyzed results it has been found that, for static load analysis, effects of earthquake force approximately same to all models except model-1(W-shape).W-shape has been found most vulnerable for earthquake load case. It is also found from the response spectrum analysis that the displacements for irregular shaped building frames are more than that of regular shaped building. The overall performance of regular structures is found better than irregular structures.
\end{abstract}

Keywords: Equivalent Static Analysis, Time History Analysis, Response Spectrum Analysis, Regular and Irregular Shape Building, Displacement, Seismic Evaluation

\section{Introduction}

Bangladesh is one of the most densely populated country of the world. Due to the large population and small per capita area, the construction of mid to high-rise buildings is becoming quite familiar in the country [1]. As Bangladesh is located in one of the most active seismic region of the world, consideration of earthquake loads in structural design has become a significant issue [2]. The behaviour of a building during an earthquake depends on several factors, stiffness, adequate lateral strength and ductility, simple and regular configurations [3]. At the time of any disaster like earthquake, cyclone or tornado, failure of structure starts at points of weakness. This weakness arises due to discontinuity in mass, stiffness and geometry of structure $[4,5]$. The structures having this discontinuity are termed as irregular structures. Irregularities are one of the major reasons of failures of structures during earthquakes [4]. Among all the factors configuration of a building is an important feature which has huge influence on the damage during the earthquake shaking $[6,7]$. The feature of the regularity and symmetry in the overall shape of the building both in plan and elevation enormously affects the response of the building under static and dynamic loading [8]. But nowadays the need and demand of the modern era and growing population has made the architects or engineers forced towards planning of 
irregular structures [9] which needs additional careful structural analysis so that acceptable behaviour of the structures can be ensured throughout a devastating earthquake [10]. So seismic analysis must be done for regular and irregular medium to high-rise buildings.

In a study, Bagheri et. al. (2012) compared the damage assessment of an irregular building based on static and dynamic analysis [11] and found greater displacement by static analysis compared to dynamic analysis. In a study of Ravikumar et. al. (2012), performance of various irregular building was observed for the hard rock region in India [3]. In Sharma's (2013) study, the effects of various vertical irregularities on seismic response of a structure has been discussed [4]. Response spectrum analysis and time history analysis was done to observe the seicmic response but equivalent static analysis was not considered in that study. He observed that the geometrically irregular shaped buildings experienced higher displacements than regular shaped building.

This study aims is to evaluate the impact of shape on earthquake response of RCC multi-storied building frames in according to BNBC-2006. The storey displacements have been obtained by using equivalent static, time history and response spectrum analysis. The results obtained are compared to determine the structural performance.

\section{Materials and Methods}

\subsection{Methods of Seismic Analysis}

Seismic analysis is a major tool in earthquake engineering which is used to understand the response of buildings due to seismic excitations in a simpler manner. In the past the buildings were designed just for gravity loads and seismic analysis is a recent development [4]. It is a part of structural analysis and a part of structural design where earthquake is prevalent. Different types of earthquake load analysis methods are used in this study those are given below.

\subsubsection{The Equivalent Static Analysis}

Dynamic nature of the load must be considered to analyse all the structures under seismic load. However, in most codes equivalent linear static methods is permitted to analyse regular, low to medium-rise buildings. It can be done with an estimation of base shear load and its distribution on each storey calculated by using formulas given in the code [12]. Then the displacement demand of model must be checked with code limitation [8]. According to BNBC-2006 displacement limitation is,

i) $\Delta<0.04 \mathrm{~h} / \mathrm{R}<0.005 \mathrm{~h}$ for $\mathrm{T}<0.7$ seconds

ii) $\Delta<0.03 \mathrm{~h} / \mathrm{R}<0.004 \mathrm{~h}$ for $\mathrm{T} \geq 0.7$ seconds

where, $\mathrm{h}=$ height of building or structure, $\mathrm{R}=$ Response modification co-efficient and $\mathrm{T}=$ fundamental period of vibration in seconds, of the structure.

In this study equivalent static analysis carried out by ETABS v9.7.1. The data used for this study are given in the Table 1.
Table 1. Necessary data for static load analysis.

\begin{tabular}{ll}
\hline Seismic zone coefficient. & $\mathbf{Z}=\mathbf{0 . 2 5}$ (zone 3) \\
\hline Soil profile type & $\mathrm{S}=1.5$ \\
Structural importance factor & $\mathrm{I}=1$ \\
Response modification factor for RCC frame & $\mathrm{R}=12$ \\
\hline
\end{tabular}

\subsubsection{Time History Analysis}

Time history analysis is a powerful tool for the study of structural seismic response [13]. It is an analysis of the dynamic response of the structure at each increment of time, when its base is subjected to a specific ground motion time history. Recorded ground motion from past natural earthquakes can be used for time history analysis [11, 14]. An earthquake ground motion records during the earthquake at 'Loma Prieta' in 1989 in Loss Angel's area has been selected for this purpose as there is no recorded data available for past earthquakes in Bangladesh region [15]. The magnitude of earthquake was 7 with ground motion having $2 \%$ probability of being exceeded in 50 years. Minimum and maximum PGA is $0.39 \mathrm{~g}$ and $0.41 \mathrm{~g}$ respectively. In this study SAP 2000 software is used for time history analysis. Details of this earthquake data are given in the Table 2.

Table 2. Data for time history analysis [16].

\begin{tabular}{ll}
\hline Parameters & Numerical value \\
\hline PGA & $409.95 \mathrm{~cm} / \mathrm{sec}^{2}$ \\
Duration of Earthquake & 25 seconds \\
Time interval & 0.01 \\
Distance from epicenter & $3.5 \mathrm{~km}$ \\
\hline
\end{tabular}

\subsubsection{Response Spectrum Analysis}

As per BNBC-2006, a site specific response spectra is required based on the geologic, tectonic, seismologic and soil characteristics associated with the specific site. In absence of a site specific response spectrum, the normalized response spectra for damping ratio $5 \%$ shall be used in the dynamic analysis [8]. BNBC response spectrum curve which has been used in this study is given in the Fig. 1. SAP-2000 is used for response spectrum analysis.

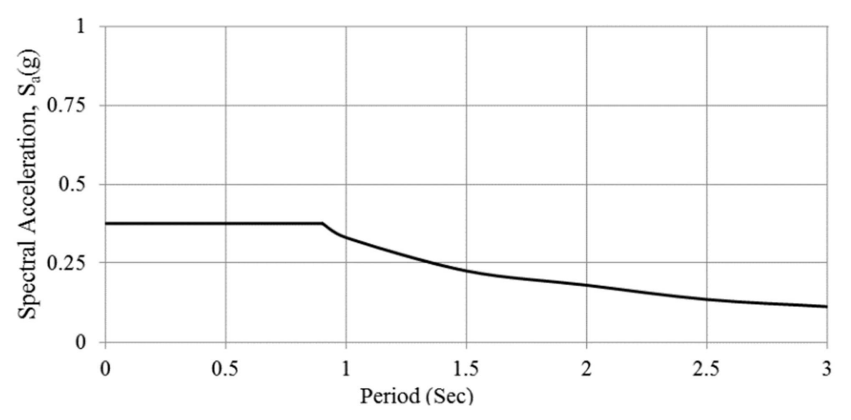

Fig. 1. BNBC response spectrum curve for 5\% damping ratio.

\subsection{Details of Models}

Among different regular structures, square and rectangular shaped structures, which are the most common shape of regular structures in Sylhet have been chosen in this study. Irregular structures, those are very common in Sylhet, have 
been selected for this study. However, this paper is focused only with plan irregularity. 2D views of Model-1 (W-shape), Model-2 (L-shape), Model-3 (Rectangular shape) and Model4 (Square-shape) are shown below in Fig. 2.

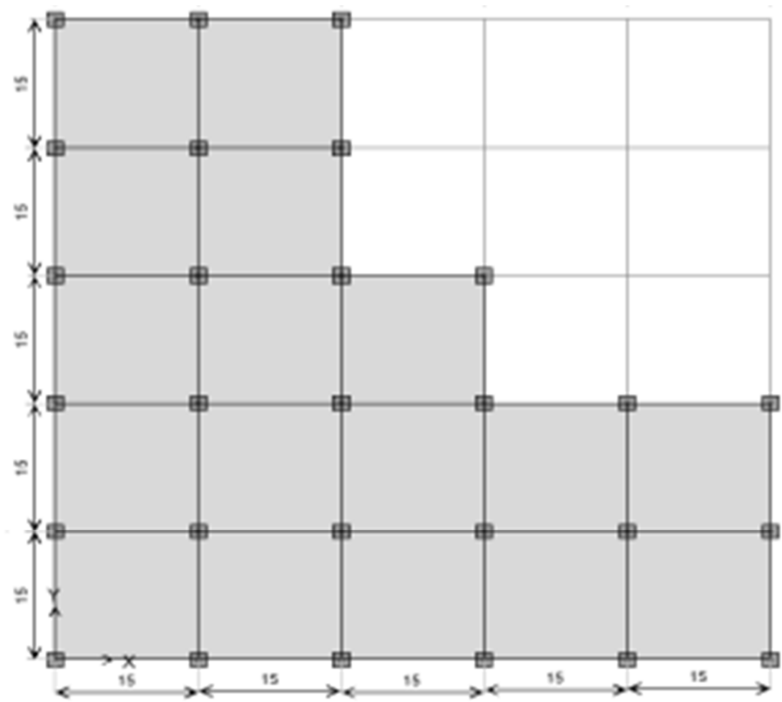

a) Model-1 (W-shape)

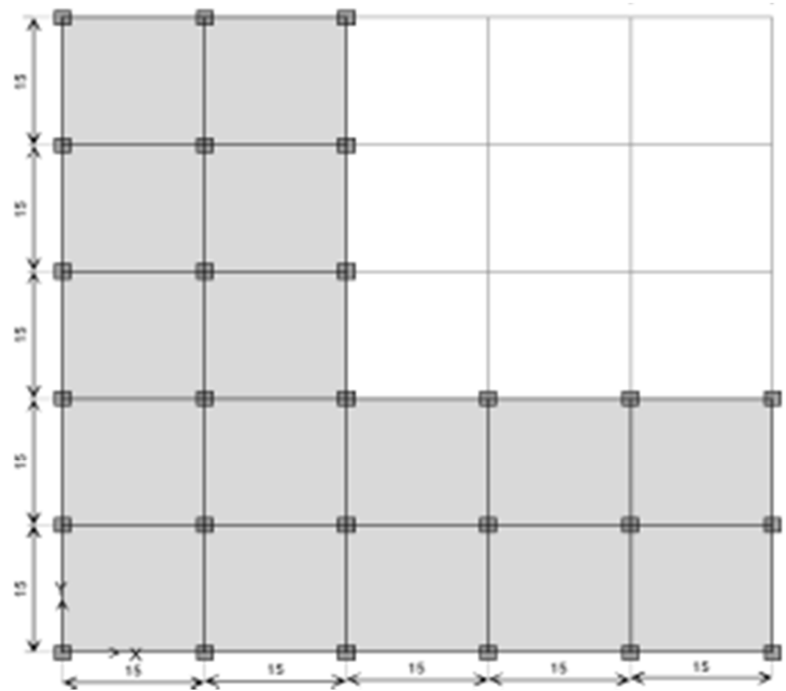

b) Model-2 (L-shape)

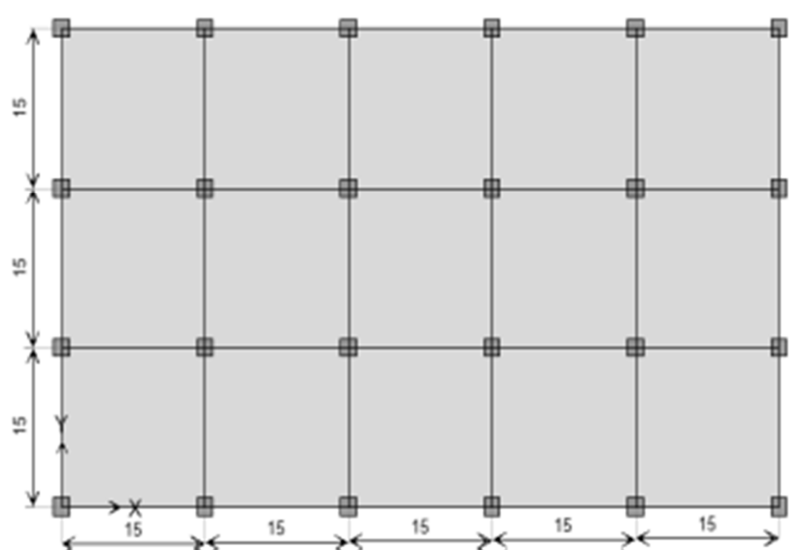

c) Model-3 (Rectangular shape)

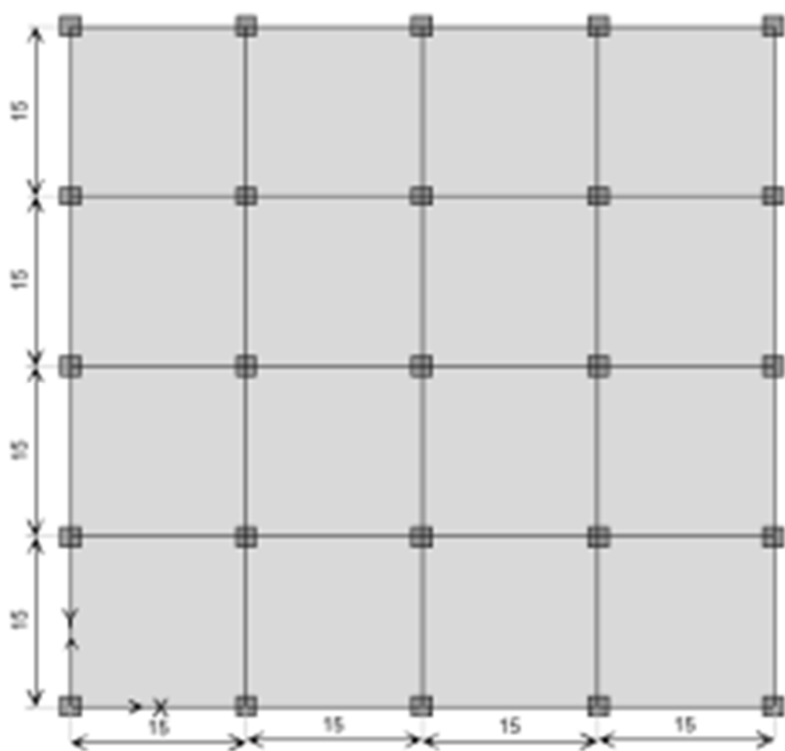

d) Model-4 (Square shape)

Fig. 2. $2 D$ view of Models.

Size of columns, beams and slabs are taken approximately for 10 storied buildings considered in this study. The area of the structures are kept close to each other to keep their influence similar. The span lengths are kept constant both in $\mathrm{X}$ and $\mathrm{Y}$ direction of different shapes. Storey height is taken as $10 \mathrm{ft}$. Loads applied on structures include dead load, live load, and earthquake load according to BNBC-2006. Structural dimension details and material properties are presented in Table 3 and Table 4 respectively.

Here the specifications are in a tabular form:

Table 3. Structural Dimensions.

\begin{tabular}{lllll}
\hline Component & Model-1 & Model-2 & Model-3 & Model-4 \\
\hline Area (sft) & 3825 & 3600 & 3375 & 3600 \\
Beam size & 18 in x 12 in & & \\
Column size & 20 in x 20 in & & \\
Slab thickness & 5 in & & \\
Height of storey & $10 \mathrm{ft}$ & & \\
Span & $15 \mathrm{ft}$ & & \\
\hline
\end{tabular}

Table 4. Materials properties.

\begin{tabular}{ll}
\hline Component & Values (unit) \\
\hline Compressive strength of concrete & $4000 \mathrm{psi}$ \\
Modulus of elasticity of concrete & $3600 \mathrm{ksi}$ \\
Shear modulus of concrete & $1500 \mathrm{ksi}$ \\
Unit Weight of concrete & $150 \mathrm{pcf}$ \\
Yield stress of steel & $60 \mathrm{ksi}$ \\
\hline
\end{tabular}

\section{Analysis Results and Discussion}

\subsection{Analyzed Result for Equivalent Static Analysis}

Base shear found from ETABS and SAP 2000 was compared with manual calculation which is shown in Table 5. From this table it can be seen that the result obtained from ETABS and SAP 2000 varies from manual calculation only by $2.03 \%$ and $0.245 \%$ respectively. 
Table 5. Comparison of base shear of Models.

\begin{tabular}{llll}
\hline Model & Manual calculation & SAP2000 & ETABS \\
\hline 1 & & & \\
2 & $4.08 \%$ of $\mathrm{W}$ & $4.09 \%$ of $\mathrm{W}$ & $3.997 \%$ of $\mathrm{W}$ \\
3 & & & \\
4 & & & \\
\hline
\end{tabular}

\subsubsection{Inter-storey Drift Index of Frames Due to} Earthquake Both in $X$ and $Y$ Direction

Inter-storey drift index due to earthquake in $\mathrm{X}$ and $\mathrm{Y}$ direction is shown in Fig. 3. From the graph it is observed that the drifts index increases from bottom storey to $3^{\text {rd }}$ storey and then gradually decreases for all models. From these figures it can also be seen that maximum and minimum drift index is observed in Model-1 and Model-4 respectively. Maximum drifts in Model-1 0.002919 whereas in Model-4 it is found 0.001604. Model-2 and Model-3 shows almost similar values of Model-4. So Model-1 shows poor performance in terms of drift index compared to other models.

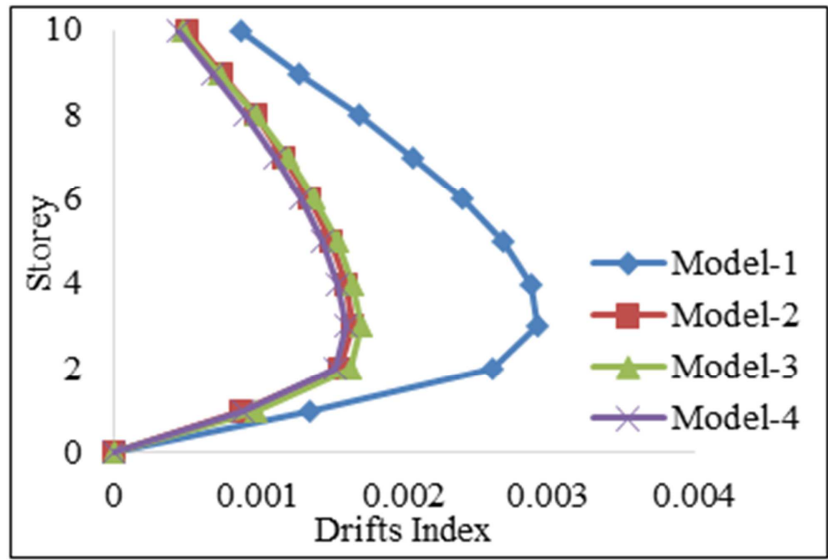

Fig. 3. Storey vs drift index for Earthquake load in $X \& Y$ direction.

\subsubsection{Comparison of Displacements for Static Load Analysis}

From equivalent static analysis, storey displacements for all structures due to Earthquake load both in $\mathrm{X}$ and $\mathrm{Y}$ directions are obtained which are shown in Fig. 4 and Fig. 5 respectively. Storey displacement is found almost similar for all the structures except Model-3 due to its change of moment of inertia in $\mathrm{X}$ and $\mathrm{Y}$ direction. It is observed that maximum displacement yields for Model-1 at every storey compared to other models whereas minimum displacement yields for Model-4. Maximum storey displacement of Model-1 is 2.4906 inch which is 1.8 times of Model-4. So Model-1 will experience more damage during earthquake. Allowable deflection is calculated for all the structures. It is found that deflections of all structures lie within allowable limit. But deflections observed in Model-1 were very close to allowable limit. So the performance of Model-1 is not satisfactory.

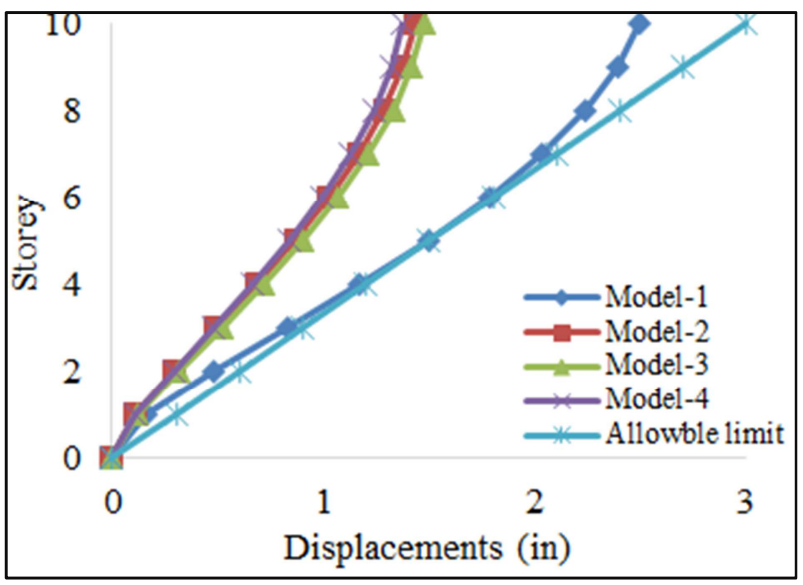

Fig. 4. Storey vs displacement for earthquake load in $X$ direction using equivalent static method.

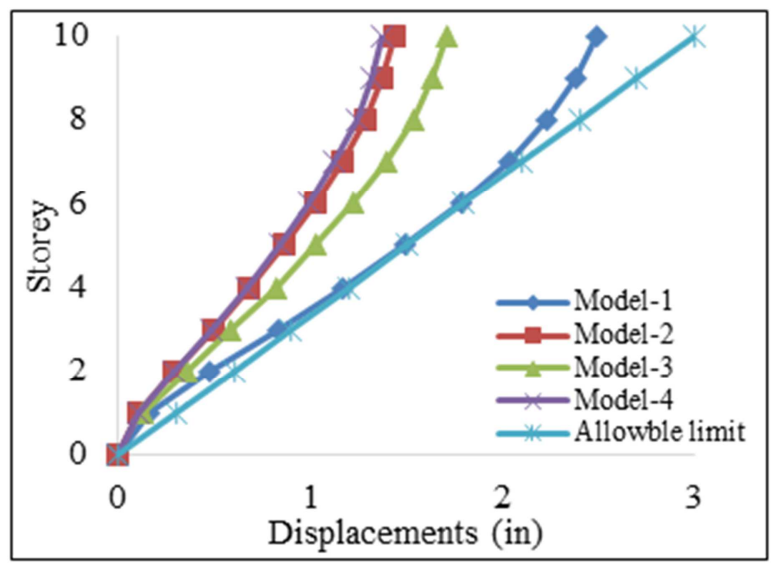

Fig. 5. Storey vs displacement for earthquake load in $Y$ direction using equivalent static method.

\subsection{Analyzed Result for Time History Analysis}

From the time history analysis storey displacements for all structures due to Earthquake load both in $\mathrm{X}$ and $\mathrm{Y}$ direction are obtained which are shown in Fig. 6 and Fig. 7 respectively. Displacements in all the structures are very close to each other. In this case, all structures exceed displacements criteria for dynamic analysis.

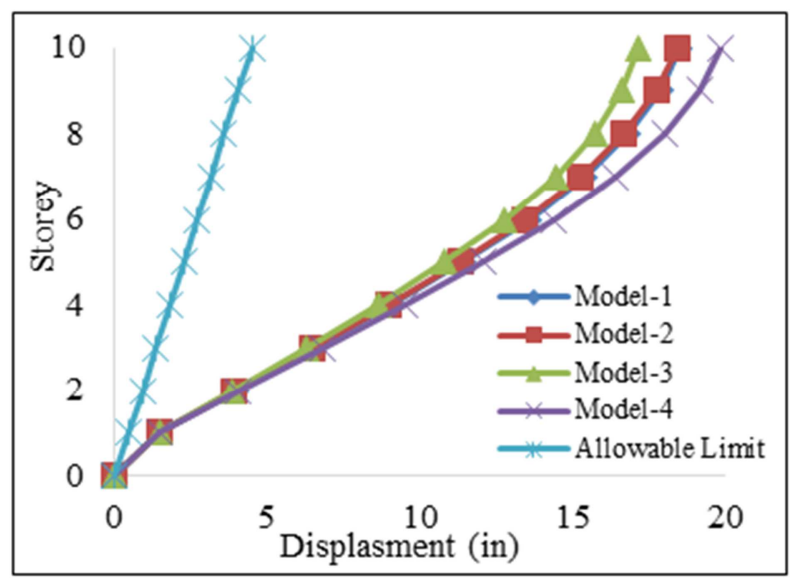

Fig. 6. Storey vs displacement in X direction using time history analysis. 


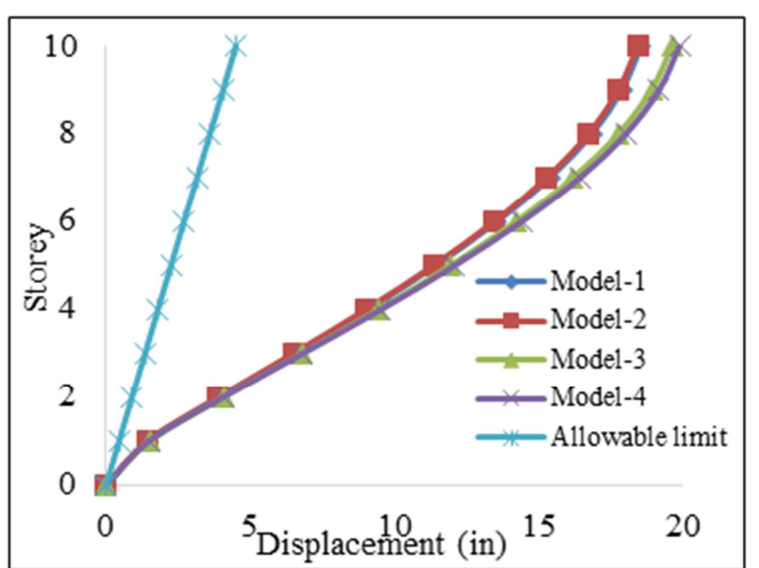

Fig. 7. Storey vs displacement in Y direction using time history analysis.

\subsection{Analyzed Result for Response Spectrum Analysis}

From the response spectrum analysis storey displacement for all structures are obtained both for $\mathrm{X}$ and $\mathrm{Y}$ direction which are shown in Fig. 8 and Fig. 9 respectively. From the graphs it is found that all the structures exceed displacements criteria given in BNBC-2006. Greater displacements are found for Model-1 and Model-2 compared to Model-3 and Model-4.

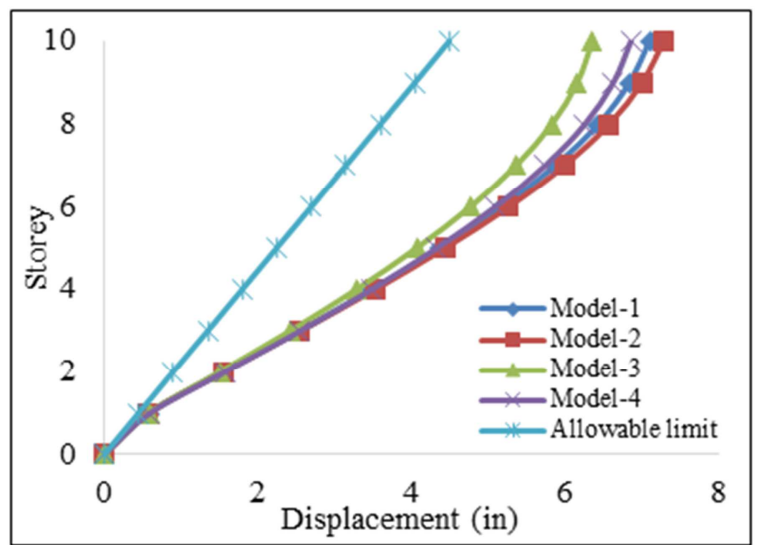

Fig. 8. Storey vs displacement in $X$ direction using response spectrum analysis.

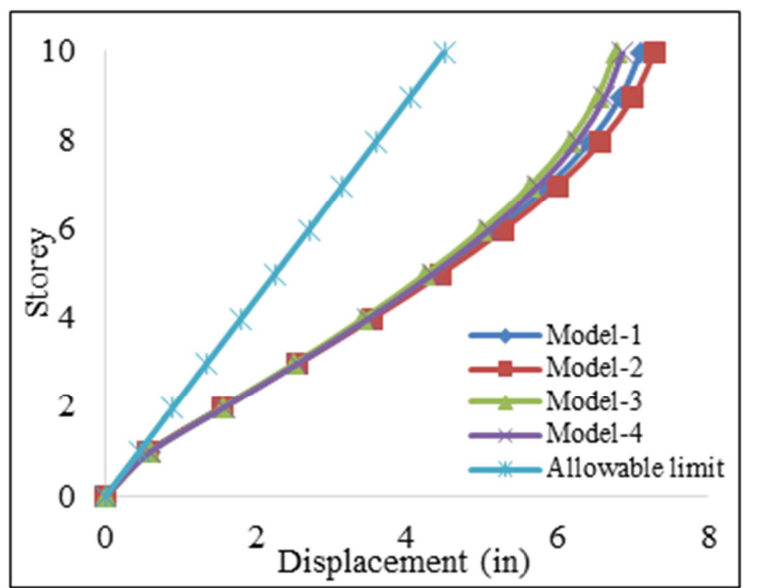

Fig. 9. Storey vs displacement in $Y$ direction using response spectrum analysis.

\section{Conclusion}

From the analysis of various shaped multi-storied buildings it is found that all structures fulfil displacement criteria for equivalent static analysis though Model-1 just touches allowable limit curve. Deflection in Model-1 has been found more than $80 \%$ from Model-4. Storey drift indexes increase with the storey height upto $3^{\text {rd }}$ storey reaching to maximum that start to decrease for all four models. Displacements obtained from the time history analysis are much higher than the allowable limit for all the Models. The difference of displacement values among all the models is insignificant since the weights of the structures are similar. From the response spectrum analysis it is also found that maximum displacement for all the structures exceed allowable limit. However, these values are much lesser than the values obtained from time history analysis. The difference of displacement values among all four shapes is insignificant in lower stories but it increased in higher stories and reached peak at top stories. Irregular shaped structures (Model-1 and Model-2) shows greater displacement than Regular shaped structures (Model-3 and Model-4). So from the overall analysis it can be conclude that performance of buildings irregular in plan is more susceptible to earthquake load than regular shaped buildings.

\section{References}

[1] Bari, M. S. and T. Das, A Comparative Study on Seismic Analysis of Bangladesh National Building Code (BNBC) with Other Building Codes. Journal of The Institution of Engineers (India): Series A, 2013. 94(3): p. 131-137.

[2] Barua, K., S. M. Hasanur Rahman, and S. Das, Performance Based Analysis of Seismic Capacity of Mid Rise Building. International Journal of Emerging Technology and Advanced Engineering, 2013. 3(11): p. 44-52.

[3] Ravikumar, C., et al., Effect of irregular configurations on seismic vulnerability of $R C$ buildings. Architecture Research, 2012. 2(3): p. 20-26.

[4] Sharma, A., Seismic Analysis and Design of Vertically Irregular RC Building Frames. 2013, National Institute of Technology Rourkela.

[5] Kumar, M. and V. G. Babu, Comparative Study of Seismic Performance of Building Having Mass Vertical Irregularity at Different Floor Levels. International Journal of Science and Research, 2016. 5(1): p. 895-899.

[6] Kabir, R., D. Sen, and M. Islam, Response of multi-storey regular and irregular buildings of identical weight under static and dynamic loading in context of Bangladesh. International Journal of Civil \& Structural Engineering, 2015. 5(3): p. 252-260.

[7] Islam, S. and M. M. Islam, Analysis on the structural systems for drift control of tall buildings due to wind load: critical investigation on building heights. The AUST Journal of Science and Technology, 2014. 5(1).

[8] BNBC, Bangladesh National Building Code. 2006: Housing and Building Research Institute Dhaka, Bangladesh. 
[9] Valmundsson, E. V. and J. M. Nau, Seismic response of building frames with vertical structural irregularities. Journal of Structural Engineering, 1997. 123(1): p. 30-41.

[10] Herrera, R. G. and C. G. Soberon. Influence of plan irregularity of buildings. in The 14th World Conference on Earthquake Engineering. 2008.

[11] Bagheri, B., E. S. Firoozabad, and M. Yahyaei, Comparative Study of the Static and Dynamic Analysis of Multi-Storey Irregular Building. World Academy of Science, Engineering and Technology, International Journal of Civil, Environmental, Structural, Construction and Architectural Engineering, 2012. 6(11): p. 1045-1049.

[12] Bagheri, B., K. A. Nivedita, and E. S. Firoozabad, Comparative damage assessment of irregular building based on static and dynamic analysis. International Journal of Civil and Structural Engineering, 2013. 3(3): p. 505.
[13] Mwafy, A. and A. Elnashai, Static pushover versus dynamic collapse analysis of RC buildings. Engineering structures, 2001. 23(5): p. 407-424.

[14] Arvindreddy and F. R. J., Seismic analysis of RC regular and irregular frame structures. International Research Journal of Engineering and Technology (IRJET), 2015. 2(5): p. 44-47.

[15] Ansary, M. and M. Sharfuddin, Proposal for a new seismic zoning map for Bangladesh. J Civ Eng, 2002. 30(2): p. 77-89.

[16] Pacific Earthquake Engineering Research Center (PEER). NGA database, http://nisee.berkeley.edu/. 